\title{
THE LACK OF STRUCTURE OF KNOWLEDGE
}

\author{
[UMA FALHA NA ESTRUTURA DO CONHECIMENTO]
}

\author{
Arthur Viana Lopes * \\ Universidade Federal da Paraíba, Brasil
}

\begin{abstract}
For a long time philosophers have struggled to reach a definition of knowledge that is fully satisfactory from an intuitive standard. However, what could be so fuzzy about the concept of knowledge that it makes our intuitions to not obviously support a single analysis? One particular approach from a naturalistic perspective treats this question from the point of view of the psychology of concepts. According to it, this failure is explained by the structure of our folk concept of knowledge, which organizes its constitutive information in a much looser way than we assume when we rely on intuitive knowledge ascriptions. I will adopt the same starting point here, but argue against the proposed answer and defend the view that this difficulty is explained not by something related to the specific structure of our concept of knowledge but, on the contrary, by its lack of structure. I claim that our folk concept of knowledge should be understood as a primitive mental state concept.
\end{abstract}

KEYWORDS: Analysis of knowledge; Psychology of concepts; Mindreading
RESUMo: Durante muito tempo, os filósofos se esforçaram para alcançar uma definição de conhecimento totalmente satisfatória a partir de um padrão intuitivo. Contudo, o que poderia ser tão confuso sobre o conceito de conhecimento que faz com que nossas intuições não suportem, obviamente, uma única análise? Uma abordagem particular de uma perspectiva naturalista trata essa questão do ponto de vista da psicologia dos conceitos. De acordo com ela, essa falha é explicada pela estrutura de nosso conceito popular de conhecimento, que organiza suas informações constitutivas de um modo muito mais vago do que supomos quando contamos com as atribuições de conhecimento intuitivo. Vou adotar o mesmo ponto de partida aqui, mas argumentar contra a resposta proposta e defender a visão de que essa dificuldade não é explicada por algo relacionado à estrutura específica de nosso conceito de conhecimento, mas, pelo contrário, por sua falta de estrutura. Afirmo que nosso conceito popular de conhecimento deve ser entendido como um conceito de estado mental primitivo.

Palavras-chave: Análise do conhecimento; psicologia dos conceitos; leitura mental

$\mathrm{F}$ or a long time now philosophers have struggled to reach a definition of knowledge that is fully satisfactory from an intuitive standard. Proposed definitions have successively faced intuitive counterexamples as we can find either cases that satisfy the criteria but do not please our intuitive judgment, or cases that do not satisfy it, but do not alarm our intuition either. This is especially salient in the period immediately after Edmund Gettier's paper (1963; Zagzebski, 1994), however,

* Professor Adjunto da Universidade Federal da Paraíba. Doutor em Filosofia pela Universidade Federal do Rio Grande do Sul.m@ilto: arthurvlopes@gmail.com 
other influential proposals have also faced the emersion of counterexamples, like the sensitivity principle (Vogel, 1987; Sosa, 2002) and the safety principle (Comesaña, 2005). Why is that? What is so fuzzy about the concept of knowledge that it makes our intuitions to not obviously support a single analysis? One particular approach from a naturalistic perspective treats this question from the view of the psychology of concepts. According to it, this failure is explained by our actual psychology, which organizes the information constitutive of concepts in a much looser way than we presuppose when we rely on intuitive ascriptions. I will adopt the same starting point here, but argue against the proposed answer and defend the view that this difficulty is explained not by something about the specific structure of our concept of knowledge but, on the contrary, by its lack of structure1.

\section{THE NATURE OF EPISTEMIC INTUITIONS}

There are different views regarding both the nature of epistemic intuitions and their role in the theorization about knowledge. The basic premise of the naturalistic view is that when epistemologists use epistemic intuitions they are trying to reveal something about our underlying concept of knowledge or justification (Goldman, 1993, 2007; Goldman \& Pust, 1998; Kornblith, 2002), and this is the starting point of epistemological theorization. Other philosophers may also assume the same premise, but have different views on what counts as an intuition and as a concept, some of which are hard to fit in a naturalistic framework. One may claim, for example, that concepts are a kind of abstract entity graspable by multiple individuals through intuitions, which in turn are a kind of rational access to these entities ${ }^{2}$. However, at least at first glance, it is not clear whether such abstract entities can occupy a place within the natural world and how exactly the access to them would work. Instead, a more obvious choice for a naturalist framework is to understand both concepts and intuitions in a psychological sense.

Thus, Alvin Goldman and Joel Pust defend that what epistemologists are doing when they consult intuition is trying to reveal something about the folk concept of knowledge as a starting point of theorization (1998). There is no mystery about the place of folk concepts in the natural world and how we can access such things. They are psychological entities and intuitions are a kind of psychological access to the content of that entity, just like our linguistic intuitions say something about the mechanisms responsible for our linguistic competence (Hintikka 1999). What we call 'the concept of knowledge' in the end of philosophical theorization need not be understood as a concept in the psychological sense - a theory is indeed something much more abstract -, but that is what we look at when we start thinking about knowledge.

The picture is made clearer when we relate a very common use of intuitions in epistemology and the default view of concepts in psychology (Lawrence \& Margolis, 1999). Epistemologists rely on intuitions in the classifications or attribution of cases, actual or imaginary. Indeed, a common starting point of conceptual analysis, in general, is to observe our ascription patterns regarding a certain kind of things and to define the concept $C$ by pulling out what is common about the cases we are willing to categorize as instances of $C$. This is the case of the analysis of knowledge. In addition, epistemologists often focus on our pre-theoretical intuitive classification as a way to test proposed analyses. When assessing one analysis, imaginary cases are constructed and our intuitive categorizations about those cases can serve as evidence either in favor of or against the specific analysis. Given the default view in psychology that concepts 
are mental representations responsible for our categorization and a number of other cognitive processes, it is simply proper to attribute those intuitions to the folk concept KNOWLEDGE ${ }^{3}$, an internal mental representation which participates in a number of cognitive processes and which allows us a reasonable understanding of knowledge in ordinary contexts.

This is precisely the target of Hilary Kornblith's critique of the traditional project. To use our pre-theoretical intuitions as the primary source of evidence, according to him, divert us from our real goal, which is to determine what knowledge really is. Instead, we will end up, at best, characterizing our folk concept of knowledge (2002). Goldman disagrees with the sharp distinction that Kornblith draws between a folk concept and what knowledge truly is and argues that our pre-theoretical concept can reveal fundamental aspects about knowledge, such as truth being "a primary basis of epistemic evaluation and epistemic achievement" (2007: p. 22). Nevertheless, their discordance is not about the nature of intuitions. Intuitions come from our folk concept of knowledge. Now, what is with KNOWLEDGE that could explain our intuitive struggle?

\section{THE STRUCTURAL HYPOTHESIS}

A further critique of Kornblith is more important here, however. The realization regarding the nature of epistemic intuitions, Kornblith claims, also implicates a pessimistic perspective about the success of any analysis. That is, even if consulting our folk concept does not consist in a diversion of the traditional epistemological endeavor, this practice is committed to a view which is highly problematized by findings of cognitive science about our actual psychology (2007). William Ramsey (1992), who, in a general critique to conceptual analysis, claims that most philosophers engaged in conceptual analysis assume something similar to the classical theory of concepts, anticipated this critique. The classical theory says that concepts are structured by underlying representations of necessary and sufficient conditions, i.e., they have a definitional structure. Since this view is proven wrong by empirical findings, conceptual analysis is doomed to failure.

This implication would come from the requirements of our standard practice of analysis. For instance, philosophers demand that "definitions be relatively straightforward and simple" (p. 60), what is illustrated by the usual way of defining a concept: " $c$ is an instance of $C$ if and only if $c$ satisfies $(. .$.$) ", where the other side of the$ biconditional is a small set of properties. Moreover, for a definition to count as robust it cannot admit any intuitive counterexample. Because one cannot achieve a short definition of $C$ which is free of intuitive counterexamples unless the concept underlying the intuitions about $C$ does not have a definitional structure itself, philosophers assume the classical view of concepts.

The argument proceeds by showing how findings of cognitive science dismantle the idea that concepts have definitional structure. Those findings, which Ramsey and Kornblith use against conceptual analysis, reveal an aspect of our processes of categorization which strongly contradicts with what we would expect if our concepts in general had a definitional structure. Furthermore, those findings ultimately motivate a general view about conceptual structure which can be used against the analysis of knowledge.

One crucial finding is that in many cases subjects can easily generate an intuitive ranking on how instances of a category are "typical", "representative", or "a good 
example" of the category in question, and that these rankings have considerable interpersonal agreement. For example, apple and peach tend to be intuitively judged as typical instances of FRUIT, whereas raisins and pumpkins are considered atypical (Rosch 1973). Also, subjects tend to first list typical instances when asked to list the instances of a category and are quicker to categorize them. If the classical view were correct, every instance of a concept would be in equal footing. They would be judged as equally good examples and there should be no disparity in the speed of categorizations. But this is not the case with countless concepts. Furthermore, there is no requirement for the properties responsible for the typicality of an instance to be necessary properties. A list of properties that predicts typicality judgments for BIRD, for example, includes "flies", "sings", lays eggs", "is small", "eats insects" and "makes nests in trees" (Rosch, 1973). None of these properties is necessary for something to be a bird.

The finding of typicality effects disproves the classical theory and demonstrates that categorization is not a "yes or no" question as drawn by a definitional view. Instead, it corroborates Ludwig Wittgenstein's (1953) claim that categorization is more a matter of family resemblance than meeting necessary and sufficient conditions. This led to the view that our conceptual system reflects statistical properties of its members. There are more and less common instances of a category, and it makes sense that the statistical experience we have with different instances generates an impression in the information we store about the category. It seems, therefore, that conceptual membership is determined not by defining properties, but by characteristic properties: $c$ is considered an instance of $C$ if $c$ has properties that are characteristic enough of $C$. Of course, only a very different kind of structure could account for these effects and the statistical view it demands.

Eleanor Rosch and her colleagues influentially claimed that the main content of a concept is a prototype, i.e., an abstract set of properties of their typical instances. We intuitively judge something to be an instance of a concept only if it is similar enough to the prototype of such a concept. As Ramsey and Kornblith note, the prototypical view can explain why analyzing a folk concept seems like an impossible task. Roughly, the problem is that a prototypical structure allows many different sets of properties, maybe even an indefinite number, to count as sufficient criteria for conceptual membership.

Suppose the prototype of $C$, which contains properties $\left\{f_{1}, f_{2}, f_{3}, f_{4}, f_{5}, f_{6}, f_{7}, f_{8}, f_{9}\right.$, $\left.f_{10}\right\}$, is listed in decreasing order of typicality. For $c$ to be intuitively categorized as $C$ it is enough for it to be sufficiently similar to the prototype of $C$, or that the sum of the typicality values of its properties reach a certain value. Therefore a number of very different instances composed by distinct sets of properties, such as $\left\{f_{1}, f_{3}\right\},\left\{f_{1}, f_{2}, f_{10}\right\}$, or $\left\{f_{6}, f_{7}, f_{8}, f_{9}, f_{10}\right\}$ can trigger a categorization. That is why very different things like a closet, a rug, and a lump can intuitively trigger FURNITURE. Therefore, Ramsey objects, any definition of $C$ in terms of necessary and sufficient conditions could not be given by a simple small set of properties, but it would contain a minimally extensive disjunction of sets, e.g. " $c$ is an instance of $C$ if and only if $c$ satisfies $\left\{f_{1}, f_{2}, f_{3}\right\}$ or $\left\{f_{1}\right.$, $\left.f_{2}, f_{10}\right\}$ or $\left\{f_{6}, f_{7}, f_{8}, f_{9}, f_{10}\right\}$ or...". To propose a simple definition to a concept with a prototypical structure is to arbitrarily treat a subset of a large or indefinite disjunction as necessary and sufficient and to submit it to intuitive counterexamples.

The suggestion of Ramsey and Kornblith, of course, is that this is the case of our folk concept of knowledge, meaning that KNOWLEDGE has a prototypical structure. Every time a definition is proposed it fails to capture all sets of the extensive disjunction that reflects our intuitive ascriptions of knowledge. And the situation worsens here where it is so easy to create the most varied sets of properties through imaginary cases. We can always manipulate the typicality values of imaginary cases by 
adding or taking out atypical and typical properties in order to produce intuitive counterexamples. This explanation is supported by the general acceptance of the prototypical theory and it places a proper emphasis in our practice of generating very imaginative cases. But do we have reasons to think it is true?

In his response to Kornblith, Goldman (2007) defends conceptual analysis by claiming that there is no obligatory commitment between the classical view of concepts and the practice of describing concepts in terms of necessary and sufficient conditions. "[P]hilosophers have customarily adopted the format of necessary and sufficient conditions, but I see nothing essential about that practice. (...) [A] recursive format could be adopted instead, using base clauses, recursive clauses, and a closure clause" (p. 24). Therefore there is no strong reason for keeping the necessary-and-sufficient format. But to say that is not to say the standard practice of conceptual analysis and the specific reason why we should give up intuitive satisfaction is still an issue. Indeed, Goldman's own view about the conceptual representation of epistemic folk concepts provides a reason for loosen the format and a distinct structural hypothesis about KNOWLEDGE.

When discussing some alleged intuitions against his reliabilist theory of justification, Goldman (1993) did not try to refute those intuitions, but to explain them by articulating the underlying representations. Goldman claimed that what causes those intuitions is the storage of exemplars. Instead of positing summary representations for categories, the exemplar theory of concepts claims that a concept stores detailed exemplars of the category, i.e., a set of detailed representations of its instances. Therefore, according to this alternative view, to have a concept $C$ is to think of $C$ as being the class of entities similar to its set of exemplars stored in long-term memory. To have FRUIT, for example, is to think of a class of objects similar to a set of objects, like an apple, a peach, a watermelon, a tomato, etc. Categorization is indeed a similarity judgment, but one that compares a particular input to one or a set of stored particular representations. Goldman says:

The hypothesis I wish to advance is that the epistemic evaluator has a mentally stored set, or list, of cognitive virtues and vices. When asked to evaluate an actual or hypothetical case of belief, the evaluator considers the processes by which the belief was produced, and matches these against his list of virtues and vices. If the processes are matched partly with vices, the belief is categorized as unjustified. (1992: p. 157).

Although Goldman's focus here is on justification, we can read his proposal as a hypothesis about KNOWLEDGE. In this case, we have a similar explanation why we cannot achieve a satisfactory short definition of knowledge. This is because the set of stored exemplars in our folk concept is too diverse to be captured by a small conjunction of conditions. For instance, considering the variety of cases and sources of knowledge, it is probable that a list of virtuous processes contains very different instances, such as beliefs formed by vision, hearing, memory, a number of approved kinds of reasoning, etc. Indeed, the exemplar view, as an alternative to the prototypical view of concepts, is in fact originally motivated by an aversion to the possibility of summary representations of a class.

We have, therefore, two distinct hypotheses about KNOWLEDGE and why it delivers the patterns of intuitive attributions that it does. What they have in common, however, is that they both share a presupposition. Both of them start from the assumption that KNOWLEDGE is a structured concept. That is, both hypotheses try to explain the difficulty of the analysis of knowledge by pointing to something in the 
structure of our folk concept, either a prototypical structure or an exemplars structure. I believe these hypotheses fail, and they fail precisely because of this basic assumption.

\section{DOES KNOWLEDGE HAVE A STRUCTURE?}

A prototypical hypothesis about KNOWLEDGE seems like a fine solution for our subject matter. The prototypical theory has a Wittgensteinian tone, which might please many philosophers and is largely accepted in the psychological literature, if not as general theory of concepts, as true about many particular concepts. We can see how its initial defense goes. Knowledge cases, ordinarily understood, are much diversified, varying between perceptual cases, testimony cases, inferential cases, and between many distinct subtypes of those cases. Surely some instances are more typical than others. Also, as previously explained, it is important to emphasize the freedom with which we create imaginary scenarios. Famous cases include people with clairvoyance powers, people with abilities to make precise measurements of ambient temperature, unexpected acquirements of abilities, evil demons, fake barns, hidden sheep, etc. The typicality of these features, its lack, or the opposite of it, could easily lead to any desired intuitive outcome. The question is whether in fact KNOWLEDGE stores statistical differences in a permanent representation. I do not think so.

The prototypical theory is mostly motivated by experiments dealing with concrete concepts, but KNOWLEDGE is an abstract concept, i.e., a concept about entities that are neither purely physical nor spatially constructed, and the prototypical theory does not apply so easily to abstract concepts. The cognitive processes that create prototypes certainly can deal with some level of abstractness. Experiments detected typicality effects relative to abstract concepts like LIE (Coleman \& Kay, 1981), CRIME, and SCIENCE, but experiments also failed to detect evidence of prototypical structure in abstract concepts like BELIEF and INSTINCT (Hampton, 1981). So, we always need to go case by case. There is no direct empirical evidence of typicality effects or its lack regarding KNOWLEDGE, but I think there are enough reasons to doubt that a prototype is responsible for our intuitive attributions of knowledge. Furthermore, those reasons equally affect the possibility of KNOWLEDGE be constituted by exemplars.

We can start by pointing out the abstractness degree of KNOWLEDGE. As a category, KNOWLEDGE is not a superordinate category like CRIME, i.e., a category whose members are themselves categories. Although we can think of subcategories of knowledge, like PERCEPTUAL KNOWLEDGE and INFERENTIAL KNOWLEDGE, their instances are not in a basic level of experience in the sense that robbery, assault and murder are, for example. It is more natural to ordinarily think about and categorize ROBBERY, ASSAULT and MURDER, than CRIME itself, for it is easier to experience, think or talk directly about the instances of those things, than the more abstract idea of CRIME. We cannot say the same about PERCEPTUAL KNOWLEDGE and INFERENTIAL KNOWLEDGE. Those ideas are much less generic than KNOWLEDGE itself, being much less identified in ordinary talk or thinking ${ }^{4}$. Because they are not in a basic level of experience, those subordinate categories are indeed improbable to be conceptually represented by most folks. On the other hand, even if SCIENCE is also not a superordinate category like CRIME and its instances are not in a basic level of experience, many of its members, such as PHYSICS, BIOLOGY, and CHEMISTRY are much more identifiable and ordinarily intelligible than categories of knowledge. This is because KNOWLEDGE is highly abstract. The degree of 
abstractness of KNOWLEDGE, therefore, renders implausible that we represent typical properties of its instances, store it in a prototype and use similarity judgments to make a categorization decision.

The same goes for an exemplars hypothesis. The exemplars theory emerged because not every psychologist was convinced about the existence of summary representations formed through the abstraction of properties from particular instances. Some of them concluded that a simpler process of conceptual learning is to store detailed representations of the instances of which the individual has relevant experiences. Because it is common to experience the more typical instances of a category, the stored exemplars of an individual normally are representative of the category. That makes sense for a lot of concrete concepts, whose distinctive properties are mostly also concrete properties and perceptually learnable, but makes less sense for a highly abstract concept.

Think, for example, about how hard it is for people to remember a situation where a property such as TRUTH occurs, in contrast to a concrete concept like CAR (Schwanenflugel, 1991), or how hard it would be for someone describe the defining properties of KNOWLEDGE in contrast with any concrete concept. To be true about KNOWLEDGE it should then simply be constituted by a number of detailed representations of instances from distinct kinds of knowledge, whose features include very abstract things like "to be true", "to have good reasons", "to have visual evidence", "to have a feeling of certainty", "to have being told by someone reliable", etc. I do not doubt we can ordinarily represent some of those features and use it in our thinking about knowledge, or that at least some of us can, but that would be a marginal content of KNOWLEDGE and acquired much later in life. To say that its main content is a varied set of detailed representations of different cases of knowledge, however, is just implausible.

The second objection also affects both the prototypical and the exemplars hypotheses. The most obvious evidence of typicality effects is the intuitive quality difference of examples from a category. A prototypical or exemplar structure leads subjects to intuitively see certain kinds of instances as best examples or representatives of the category. Hence, it makes intuitive sense to say that the best case of LIE is one in which what is being told is false. The speaker knows that what he or she is telling is false, that they have the intention to deceive, and that a situation in which the speaker does not know they are telling a falsehood is also a case of a lie, but a "weaker" case, in a way (Coleman \& Kay, 1981). Similarly, it is common to think of murder and robbery as good examples of CRIME, while not using your seatbelt when driving (in Brazil), throwing out a mail that arrived to your house by mistake, or adultery (in the United States) as not so good examples. Meanwhile we think of physics and chemistry as good examples of SCIENCE, while many do not feel the same about cartography or linguistics. Although the ideal test here is obviously empirical, we can make an armchair case for the claim that KNOWLEDGE is not equivalent to these abstract concepts in this respect.

Instances of knowledge are very diverse. We attribute knowledge to children, animals, information acquired by perception, inference, testimony, explicitly justified beliefs, etc., and every case is particular to a specific situation and context. If such diversity were organized by a summary representation defined by statistical information or a limited set of exemplars it would be only natural to think of some of them as being better examples than others, but despite such diversity, our intuitive categorizations of knowledge do not vary qualitatively with regard to their representativeness. Intuitively, there is no difference, for instance, between knowing that the dog entered the house by 
seeing it, by hearing it, by inferring it, or by being told by someone, in the sense that none of them is a better example of knowing than the others. This is the general case of our intuitive categorizations of knowledge. Once we categorize something as a case of knowledge, it just feels like as good of a case as any other, which is different from what happens in a concept clearly structured in terms of a prototype or exemplars.

The point, precisely, is that typicality effects are certainly not a robust phenomenon in the case of KNOWLEDGE. There are detectable differences of quality regarding the evidence of someone that knows something, but this is not a matter of representativeness. Also, bizarre cases, such as clairvoyance and the sudden ability to measure ambient temperature, or more mundane unclear cases of belief, are likely intuitively strange whenever they do not fit the body of beliefs of someone about the world or provoke an hesitant categorization, respectively, but, again, this is a different matter. Lastly, it is prudent not to entirely rule out the possibility that some judgment about representativeness can be found, especially because that is essentially an empirical matter, but I reject the significance of those as evidence of a prototypical or exemplars structure 5 . If KNOWLEDGE really consisted in permanent representations like a prototype or exemplars, we should easily find cases that are intuitively more representative, but those are not easy to find.

\section{KNOWLEDGE AS MENTAL STATE CONCEPT}

Since these two structural hypotheses fail, we need another answer for our central question. So what is it about KNOWLEDGE that explains the difficulty of finding an intuitively satisfactory definition of knowledge? Instead of discussing any other possible structures, in the next two sections I want to propose a radically distinct hypothesis. Concepts are initially divided into primitive concepts, which are not constituted by any other concept, and complex concepts, which are formed by simpler or primitive ones. A fundamental goal of a general theory of concepts, therefore, is to explain how complex concepts are psychologically organized and very different structures were postulated in psychological literature, including exemplars and prototypes. Given the influence of statistical approaches and the epistemological orthodox view that knowledge is a composite state of things, it seems natural to assume, as some philosophers did, that KNOWLEDGE is a complex concept, one whose fuzziness is explained by statistical differences determining its structure. I will argue, however, that this is actually a primitive concept.

A first step here is to determine the kind of category that KNOWLEDGE represents. When discussing the prototypical and the exemplars hypothesis, I claimed that these do not fit well to the type of abstract concept that KNOWLEDGE is, but what specific kind of abstract concept is it? What BELIEF and INSTINCT have in common is that they are mental states concepts, and the fact that they constitute a particular form of abstract concept allows us an explanation for their failure in having a prototypical or exemplars structure. Instances of mental states patently are entities that cannot be directly observed. There is nothing perceptually obvious about most mental states, so it would make sense that without more salient properties, our concepts about them would not be essentially constituted by prototypes or exemplars. The imminent suggestion, of course, is that KNOWLEDGE is itself a mental concept.

This suggestion gains plausibility if we note that the general description of mental states concepts fits well with what we found out about our case of interest. For example, Anna Papafragou and colleagues said about mental verbs that: 
[T]hey do not refer to perceptually transparent properties of the reference world; they are quite insalient as interpretations of the gist of scenes; (...) the concepts that they encode are evidently quite complex or abstract; and they are hard to identify from context even by adults who understand their meanings. (Papafragou et al. 2007: 126)

I take the lack of properties that can perceptually identify its particular instances as an indication of the nature of KNOWLEDGE as a mental state concept. This idea, however, certainly finds resistance from the epistemological literature. The problem is that it seems to collide with ideas from the orthodox view on the nature of knowledge. For instance, how could it be a mental concept if the idea that knowledge is composed by belief and other non-mental properties such as truth, for example, is intuitively supported? However, there is no inconsistency here. It is perfectly possible that although we can infer from our categorizations that a knowledge state is composed by a state of belief plus other properties, like truth, KNOWLEDGE itself does not contain this information properly represented. It may be that from the understanding of a folk concept, knowledge is not composed by belief plus other properties ${ }^{6}$, and that a proper mental state can in fact consist in a factive state. Nothing that motivates the composite assumption prevents that.

Unlike the doubts that may come from someone immersed in epistemological views, in the psychological literature KNOWLEDGE is constantly listed as just another mental state concept alongside BELIEF, DESIRE, INTENTION, etc. (Premack \& Woodruff, 1978; Apperly, 2011; Baron-Cohen et al., 1994; Call \& Tomasello, 2008; De Villiers, 2007). This happens in developmental, comparative, and social psychology. More specifically, such classification figures in research on our mindreading abilities, which puts KNOWLEDGE as one of the conceptual components of our theory of mind and raises certain questions like: At what age do children start to track the knowledge of others? What are the kinds of processes which allow us to discriminate knowledge? To what extent can nonhuman animals track the knowledge of others?

One may worry that we are changing the subject by adopting this notion because they doubts that psychologists mean the same thing as philosophers by "mental state" when they speak of subjects tracking knowledge. For one thing, factive states are not mentally localized, so what is the point of including KNOWLEDGE as a component of our mindreading abilities if knowledge is not actually a mental state? This doubt, however, is unwarranted. The resistance to this conception presupposes that it is not possible that the natural way we understand mental states already incorporate relations between the agent and the world, including a factive relation. But nothing in it prevents this. In contrast, this is part of the reasoning behind the psychologist's view about knowledge being in fact a mental state. That is, psychologists readily accept that our mindreading processes are partly performed by taking into account relations between the agent and the world. More important, this is properly supported by the empirical evidence. Most of the cognitive tasks regarding folk's attributions of knowledge, ignorance, and false belief, for example, consist precisely in testing subjects' ability of tracking specific relations. Again, under the framework of our folk theory of mind, KNOWLEDGE can perfectly be a mental state concept.

In what follows, I will endorse the view that KNOWLEDGE is a mental state concept. Note, however, that one can concede the psychologists' point and still deny that knowledge really is a mental state. I will not try to argue in favor of the stronger position that the state of knowledge really is a mental state (Williamson, 2000). Again, although I claim that we use KNOWLEDGE to theorize about knowledge, a theory about the former is not a theory about the latter. As far as this is a metaphysical matter I 
doubt that evidence from psychology, which is what concerns us here, can solve it. In contrast, I think it is reasonable to trust in the psychological literature to help us settle certain matters regarding our folk concept of knowledge, especially when it comes to questions about which the empirical evidence has much to say.

\section{Simulation AND Mental STATE CONCEPTS}

Given that we are dealing with a mental state concept, the investigation on its structure now necessarily goes through the working of our mindreading abilities. There are two main general views regarding our mindreading abilities, the theory-theory (TT) and the simulation theory (ST), which stand for two sides of a long debate about how we are capable of mentalizing. Each of these views refers to a number of particular theories, making the dispute too complex to be discussed in detail. One issue, for instance, concerns the possibility of specific versions of those theories implying a collapse of the theories (Davies \& Stone, 2001). For our purposes, it is enough to say that I interpret the two as implying substantively different things regarding the nature of mental state concepts. In particular, the simulation theory is an "information-poor" approach to mindreading, while the theory-theory is "information-rich" (Goldman, 1995). As long as the supposed collapse implies an information-poor view of mental concepts, it does not affect the thesis that I advocate here, which relies on the framework of the simulation theory.

The TT approach to mentalizing follows a paradigm in cognitive science in which a number of cognitive abilities are explained by the postulation of internally represented information structures, i.e., a set of representations and principles. Those principles consist in rules or laws relating elements of a certain domain and constitute the agent's understanding of it. Because the principles operate on representations of things from the domain, those structures are equivalent to an interpretation or theory of that domain. ST, in its turn, explains our capacity of mentalizing by mechanisms that do not require theoretical information. Its advocates claim that mindreading requires no internally represented structures about both what mental states are and about psychological rules. They find the possibility of folks acquiring psychological generalizations and meta-representations about mental states especially doubtful, but they also doubt the need for innate meta-representations.

The central thesis of ST is that mindreading is achieved by a particular use of the agent's own cognitive apparatus. Roughly, we form predictions and explanations of someone's mental states by "putting ourselves in the other's shoes", running our own cognitive mechanisms and seeing the resulting psychological states. In other words, we do not need to develop a folk theory about the working of others' behaviors because we have a perfect behavior-producing mechanism ourselves and we can use it as a model to understand others. Because we share similar cognitive mechanisms and principles, to use this model allows successful predictions of others' psychological states. Take an example from Daniel Kahneman and Amos Tversky on counterfactual reasoning.

Mr. Crane and Mr. Tees were scheduled to leave the airport on different flights, at the same time. They traveled from town in the same limousine, were caught in a traffic jam, and arrived at the airport 30min after the scheduled departure time of their flights. Mr. Crane is told that his flight left on time. Mr. Tees is told that his flight was delayed and just left five min ago. Who is more upset? (Kahneman \& Tversky, 1982: 203)

Unsurprisingly, the overwhelming majority of subjects $(96 \%)$ answered that $\mathrm{Mr}$. 
Tees is more upset than his limo colleague is. Simulationists see this piece of mindreading as a representative case of simulation. So how are we able to simulate Mr. Crane's and Mr. Tees's states and compare them? One obvious obstacle is that we are not really in their situations. We are not in a limo on our way to the airport trying to catch a flight, nor are we in any of their specific situations of delay. In order to properly predict the resulting state of someone, simulation requires a way to use the other's relevant initial states as input. Accordingly, simulationists attribute a fundamental role to imaginative processes in cases like this. One way we could overcome the initial interpersonal distance is by generating pretend states that are relevantly similar to those of the target (Goldman, 2006). After creating pretend states of the relevant initial states of Mr. Tees and Mr. Crane, we can just run them into our own cognitive system for, lastly, checking what their resulting states are like.

Similarly, to predict someone's decision or epistemic state about a certain matter, we create pretend states that enact his initial states, which can include propositional attitudes, and we run them into our own decision-making mechanism. Obviously, however, we do not process these pretend states as we normally process the inputs we find in tasks not related to mindreading, we have to make the system "off-line", i.e., disconnected from our action-controllers. Computationally, thereby, simulation just requires the co-optation of existing mechanism, instead of the computation of an entire body of information. Importantly, however, a consequence of this co-optation is the necessity of "quarantine" or inhibition of the agent's own states when running his cognitive system. (Goldman, 2006). The agent's own mental states must not interfere in the process or else it may no longer resemble the target's processes. Failure to do so leads to an egocentric bias by the agent.

Since we use or own cognitive apparatus as a model to predict others' states, simulation dismisses the necessity of internally represented structures about what mental states are or about psychological rules for mindreading. We can predict and attribute mental sates to others without storing information about mental states. However, we obviously can think about mental states. We make attributions, talk about them, and we even think about them in counterfactual situations. To do this we use some sort of representation and, assuming just the default view of concepts that take them as the constituents of thoughts, we can say that we do have concepts which are about mental states. So in what does a mental state concept consist of under this framework?

Alvin Goldman's proposal on mindreading provides a clear view about how mental concepts can be involved in simulation. According to his theory, first-person attribution plays an essential role in mindreading. Roughly, one needs to detect, introspectively, one's own mental states in order to attribute them to others. He says:

My central thesis is that mental concepts (partly) employ introspection-derived, or introspection-associated, mental representations. There is a proprietary code, the introspective code (I-code), used to represent types of mental categories and to classify mental-state tokens in terms of those categories. (2006: 260).

In other words, the I-code consists of properties which are accessible to introspection. Instantiation of mental states also instantiates those properties, and an agent classifies what mental state he is in virtue of them. Goldman uses "partly" because he does not exclude the possibility of other kinds of representations also being part of the representations that are used to classify a mental state. However, he is careful to say that the "vast majority of self-attributions of current mental states, I suspect, use introspection only" (2006: 263). 
Since third-person attribution fundamentally depends on first-person attribution, it is possible that certain mental concepts consist only in introspective classification. Assuming this is true for DESIRE, for example, instantiations of DESIRE consist only in certain mental states tokens being recognized by the agent as pertaining to the same state kind. Given that introspective classification is a "perception-like process", DESIRE is essentially a recognitional concept. A recognitional concept is a concept whose possession conditions include a recognitional requirement according to which one needs to have the ability to recognize instances of the things that fall under that concept (Fodor, 1998). Importantly, one needs to possess no descriptive content or informational structures in order to possess a recognitional concept. Furthermore, even if a concept is constituted only by a recognitional ability, one can still talk about it, think about it, or use it to compose new thoughts or concepts. The meaning of this concept is just the entities to which it refers. Thus, when one thinks and talks about DESIRE, one refers to the states one recognizes as desire states.

Applying this idea to KNOWLEDGE, a surprising hypothesis arises: KNOWLEDGE is a recognitional concept, that is, it consists only in the ability to recognize and classify certain instances of mental states as pertaining to the same kind of mental state. Assuming the existence of an I-code, KNOWLEDGE is a primitive concept which consists only in the ability of recognizing a particular class of internal states, which we shall call $k$-states. I do not take k-states in the same vein of Williamson (2000), i.e., as identical to knowledge states. $k$-states are simply the class of mental states classified by our cognitive system as this proper mental state, that have this proper internal status. It is what our cognitive system treats as knowledge. So, contrasting with all hypotheses we saw so far, we have a non-structured hypothesis: what underlies our ordinary understanding of knowledge is a primitive concept. No structure, however, do not mean no concept. What we need now is to assess this proposal. How plausible is the idea that our ordinary understanding of knowledge consist only in recognizing a certain kind of mental states?

\section{KNOWLEDGE AS PRIMITIVE MENTAL STATE CONCEPT}

This is a radical change of perspective for anyone who assumed that the term 'understanding' fundamentally involves some sort of substantive internal content or a body of stored information. The previous hypotheses followed this assumption, but we simply do not need such substantive content to think about knowledge. Our folk concept of knowledge consists only in the ability to discriminate $k$-states, one that is supported by introspection and simulative processes.

We can initially favor this thesis by noting that we should have a way to recognize the internal statuses of certain states. Humans are "information processors", machines that self-regulate the information that it is produced and processed from interaction with the world, and it is quite obvious that many pieces of information are internally treated as pieces of knowledge. Countless outcomes of perceptual processes seem to have the internal status of knowledge, some actions are carried forward only if the reasons that motivate them are taken as knowledge, and the outcomes of reasoning processes have such a status only if the status of their inputs, individually or collectively, are good enough according to some determinate standards. Our cognitive system must have a way to recognize this internal status. Thus, one may claim that $\mathrm{k}$ states are simply one kind of status that may be attributed to certain information available to the cognitive system ${ }^{7}$. But do we have positive evidence that this is the 
case?

The stronger evidence we can find for the simulation hypothesis is in the experimental literature regarding egocentric effects in our reasoning about mental states. This literature concerns a number of particular tendencies we have of both overestimating our own mental states and attributing others with aspects of our own viewpoint. This is common theme in the developmental literature, in which children are often described as egocentric (Piaget \& Inhelder, 1956). More importantly, these effects include a specific class of errors or biases regarding the attribution of knowledge, constituting what is called epistemic egocentrism, which are not restricted to children.

Epistemic egocentrism is the tendency we have to both overestimate our own epistemic state and the epistemic states of others in a more naïve situation. ST naturally predicts egocentric effects. To successfully predict someone's mental state one needs to put their own mental states in "quarantine", to inhibit them from entering in the simulative process, otherwise they will interfere in the process and no longer resemble the target's states. If mental state attribution is a matter of having the right theory, on the other hand, then egocentrism should not be such an issue.

A famous example of epistemic egocentrism is what is called the hindsight bias or "knew-it-all-along effect". This bias is characterized as the tendency to see past events as having been more predictable than actually was the case, making us believe that we knew they would occur, even when evidence indicates the opposite. In an influent study, Baruch Fischhoff (1975) asked people to judge the likelihood of some historical events based on written descriptions of them. Participants were presented with a short story with four possible outcomes and asked to assess the likelihood of each individual outcome, one group of participants was informed of the actual outcome of the story. Fischhoff found that participants in the informed group were much more inclined to attribute higher likelihood to the outcomes they were told to be true. This result is representative of the difficulty we have to suppress the knowledge available for us when assessing our previous situation. This bias is easily explained by a simulationist hypothesis. The problem in these cases is that the agent's k-states interfere in the simulative process. On the other hand, what pieces of theory could explain these errors? More generally, even if one develops an explanation in the terms of TT, it is simply implausible that every instance of the widely reported cases of epistemic egocentrism, in children and adults (Birch \& Bloom, 2003), is explained by theoretical mistakes.

The literature on epistemic egocentrism provides the best empirical evidence in favor of the evidence proposed here, but we can make a much more stronger case for it by speculatively approaching the working of k-states, epistemic egocentrism and the normativity of knowledge. Although this has been overlooked so far, the concept of knowledge is often described as a normative concept in the literature. Reasoning about knowledge, one may claim, has to do with reasoning about the correct attitude regarding a proposition. Accordingly, some epistemic intuitions are obviously normative, they evaluate that one should not have assumed that attitude, or that that attitude is appropriate, etc. So, one relevant question is: what is the relation between normativity and KNOWLEDGE?

The answer here is that no explicit normative judgment is constitutive of KNOWLEDGE. We can surely make conscious judgments about what people should do or think in order to achieve knowledge, but those do not compose the content of this mental state concept. Nevertheless, normativity judgments still have a crucial relation with k-states. I believe it makes more sense to understand normativity through the procedural norms that determine our rational reasoning (Pollock, 1995). That is, we 
have tacit rules or principles that authorize or prohibit certain steps in processes like factual reasoning, logical reasoning, insights and other intuitive processes, causal reasoning, etc., whose resulting outcomes may be or not be considered as k-states by our reasoning system. Just as well, procedural norms determine the normative steps involved in reasoning, including conscious normative judgments; they also determine the production of k-states, i.e., the states that are treated by our cognitive system as knowledge.

Accordingly, we can speculate that we use normative judgments to categorize others' epistemic states through simulation. When judging a certain subject matter, procedural norms give us personal normative judgments about how to proceed, what to think, what to conclude, etc., about the matter. It is plausible, therefore, that when one simulates another's mental state regarding a particular subject matter, those normative judgments can constitute part of the simulative process, especially if the matter or situation triggers more conscious reasoning. In other words, to assess $S$ 's epistemic state, regarding $p$, the agent needs to run his own cognitive mechanisms regarding $p$, and these mechanisms may include normative judgments.

This opens the possibility of particular cases of egocentrism. For instance, if one fails to inhibit his or her own mental states when simulating $S$ 's mental state regarding $p$, this affects one's normative judgments about how to proceed or about what one is authorized to conclude, resulting in an inaccurate simulation of $S$ 's mental state. It is possible, therefore, that an agent fails to detect that $S$ is in a k-state because failing to inhibit their own mental states when running his cognitive mechanisms causes them to judge that $S$ is not authorized to be in a k-state. This would happen, for example, in cases in which the agent is in a privileged evidential position with respect to $p$ in comparison to $\mathrm{S}$, either because they misrepresent $\mathrm{S}$ 's reasoning, or because their perspective makes them to normatively disapprove S's resulting mental state.

This idea, indeed, is already present in the philosophical literature. Jennifer Nagel has recently used the notion of epistemic egocentrism to explain certain patterns of epistemic intuition like the error effect (Nagel, 2010, 2012). Although she remains neutral about the dispute between ST and TT and the more specific details of the conceptual processes involved in simulation, her psychological analysis is more naturally accounted by ST and a hypothesis like the one defended here. In particular, a simulative process explains the fact that when error possibilities are made salient about a certain case we become more stringent about knowledge ascription.

Nagel develops her argument by pointing to the existence of different strategies of reasoning and how they affect our mindreading processes. We have different cognitive strategies to deal with problems and they can vary with respect to the effort they expend. One common division separates "low" strategies, which are heuristic and effortless in character, and "high" strategies, which are more effortful, sequential and conscious in character, typically involving the consideration of alternatives. This division follows the dual process theory, a general psychological theory that says there are at least two distinct types of processes underling a number of different psychological processes (Frankish \& Evans, 2009), including mindreading, social judging, categorization, probability assessment, etc. Importantly, two distinct processes can produce different outcomes for the same problem, e.g., a subject can make a certain probability assessment through a heuristic processes, and deliver a different outcome through a more slow and conscious reasoning. Those processes vary in accuracy according the conditions they are triggered.

Nagel notes that the conditions in which we judge "skeptical pressure cases" causes us a high-level process of judgment. We are told a possibility of error and 
induced to think about the epistemic consequences of this alternative situation, so we assume a sequential reasoning. She then proposes that we do not really represent subjects in skeptical pressure cases as thinking like us, with a more elaborated strategy, but that we use this higher strategy as a "benchmark" to evaluate the subject's situation. In other words, possibilities of error induce us to think what would be necessary to know in those alternative situations and we use that reasoning as a benchmark to evaluate the epistemic situation of others. Therefore, the fact that we have different reasoning strategies to deal with one same situation is a source of intuitive "instability" is very important for our investigation,

This psychological analysis is in perfect tune with our simulationist account of KNOWLEDGE. The error-effect is naturally explained as an instance of simulative mindreading. We evaluate a subject by "trying" to put ourselves in their shoes, but having certain possibilities of error brought to attention to - say the possibility of a clock on which he usually relies being actually broken in that moment - we adopt a different reasoning strategy than what the subject would adopt. That is to say, we adopt distinct procedural rules from those of the agent, and somehow intuitively "disapprove" either of their resulting mental state or their reasoning strategy. Furthermore, the fact that the standard way epistemologists ask for intuitive categorizations is through the description of imaginary situations is another reason for believing that the standard way we come to these ascriptions is through the imaginary component of simulative mindreading.

We now have an answer for our central problem. Because the standard way we intuitively categorize others' epistemic states is through our own cognitive system, in a simulative way, those categorizations are subjects to the kinds of factors that affect the inner epistemic statuses of our own internal states. The existence of different and independent reasoning strategies and the strong tendency of an egocentric perspective are a constant source of intuitive counterexamples to proposed analyses. As many imaginary cases describe situations where the epistemic agent is in a more naïve condition than we are, as evaluators, for example in cases where we are told about possibilities of error unknown by the agent, we egocentrically judge their mental states from our normative point of view. Even worse, because it is always possible to artificially create cases where the agent is in a more naïve situation then the evaluator and create facts that trigger a more rigorous reasoning strategy, it is always possible to create intuitive counterexamples to proposed definitions.

\section{FinAL THOUGHTS}

We investigated the naturalistic perspective on why it is hard to find a definition of knowledge that is not intuitively troubling. I argued against the primary answer from Kornblith and others that the problem is in the structure of KNOWLEDGE, the folk concept underlying our intuitive knowledge attributions. This answer assumes that such structure reflects statistical differences of knowledge instances, which gives the concept a much looser boundary in comparison to a definitional structure. I presented several reasons that support the notion of this particular structural approach being incorret, and then argued that actually any structural assumption is mistaken. Our intuitive epistemic ascriptions do not come from a specific representation whose structure generates intuitions not consistent enough for the purposes of analysis. There is no representation, even if vague, that determines what counts as knowledge. There is no structure. The folk concept that triggers such categorizations consists in a primitive concept of a 
mental state, the ability to identify an inner code that provides a particular epistemic status to certain types of internal states

The production of such an inner code is determined by our cognitive system, which decides what epistemic status each piece of information processed by it should receive. Because the way one has to identify those internal states in others, to "read their minds", utilize his own cognitive system, our epistemic categorizations are subject to effects that commonly prevent intuitive consistency for an analysis, like the strong tendency for egocentric perspective and the existence of different and independent reasoning strategies in human cognition. A point of clarification is important here, however. I do not want to claim that simulation is the only way to get to a categorization of knowledge. The view defended here is that simulation is the standard way we attribute or deny knowledge to others, especially in the context of assessing imaginary scenarios. But I want to leave open, for example, the possibility of us having generalizations regarding KNOWLEDGE ${ }^{8}$. This is probably also a common way we intuitively attribute knowledge to others and ourselves and a possible of intuitive trouble. I do object, however, that those generalizations are constitutive of the folk concept itself. Instead, the concept is a component of them.

Finally, it is an open question the exact implications of the view defended here for conceptual analysis. Whether we should reject every instance of egocentric intuition as having no evidential value, whether we should make sense of them in theory, or what KNOWLEDGE refers to given that it is a primitive concept, for example, are questions that we leave to another discussion.

\section{REFERENCES}

AIKHENVALD, A. (2004). Evidentiality. New York, NY: Oxford UP.

APPERLY, I. (2011). Mindreaders: The Cognitive Basis of "Theory of Mind". Hove and New York: Psychology Press.

BARON \& COHEN, S. (1994). The eye direction detector (EDD) and the shared attention mechanism (SAM): Two cases for evolutionary psychology. In C. MOORE \& P. DUNHAM (Eds.), The Role of Joint Attention in Development (pp. 41-59). Mahwah, NJ: Erlbaum.

BEALER, G. (1998). Intuition and the Autonomy of Philosophy, In DePaul, M. and Ramsey, W. (eds.) Rethinking Intuition. Oxford: Rowman \& Littlefield Publishers, Inc., 201-39.

BIRCH, S. \& BLOOM, P. (2007). The curse of knowledge in reasoning about false beliefs. Psychological Science, 18(5), 382-386.

COLEMAN, L., \& Kay, S. (1981). Prototype semantics: The english word LIE. Language 57: 2644.

COMESAÑA, J. (2005). Unsafe Knowledge. Synthese, 146(3): 395-404.

DAVIES, M. \& Stone, T. (2001). Mental simulation, tacit theory, and the threat of collapse. Philosophical Topics, 29, 127-173.

DE VILLIERS, J. (2007). The interface of language and Theory of Mind. Lingua, 117(11), 18581878.

FISCHHOFF, B. (1975). Hindsight $\neq$ foresight: The effect of outcome knowledge on judgment under uncertainty. Journal of Experimental Psychology: Human Perception and Performance, 1, 288-299

FODOR, J. (1998). There are no recognitional concepts - not even RED In In Critical Condition, Cambridge, MA: MIT Press, pp. 35-47.

FRANKISH, K., \& EVANS, J. (2009). The duality of mind: an historical perspective. In K. Frankish \& J. Evans (Eds.), In Two Minds: Dual Process Theory and Beyond (pp. 1-29). Oxford: Oxford University Press.

GETTIER, E. (1963). Is Justified True Belief Knowledge? Analysis, 23: 121-123. 
GOLDMAN, A. (1993). Epistemic Folkways and Scientific Epistemology. Philosophical Issues, 3, p. 271-285.

GOLDMAN, A. (1995). In defense of the simulation theory. In M. Davies and T. Stone (eds.), Folk Psychology. Oxford, Blackwell, pp. 191-206.

GOLDMAN, A. (2006). Simulating Minds. Oxford, Oxford University Press.

GOLDMAN, A. (2007). Philosophical Intuitions: Their Target, Their Source, and Their Epistemic Status. Grazer Philosophische Studien 74: 1-26

GOLDMAN, A., and Pust, J. (1998). Philosophical Theory and Intuitional Evidence, in M. DePaul and W. Ramsey, (eds), Rethinking Intuition: The Psychology of Intuition and Its Role in Philosophical Inquiry, 179-197, Rowman \& Littlefield.

HAMPTON, J. (1981). An investigation of the nature of abstract concepts. Memory and Cognition 9 (2).

HINTIKKA, J. (1999). The Emperor's New Intuitions. Journal of Philosophy 96(3), 127-147.

KIM, M., and YUAN, Y. (2015). No Cross-Cultural Differences in the Gettier Car Case Intuition: A Replication Study of Weinberg Et Al. 2001. Episteme 12 (3):355-361.

KIM, M., and YUAN, Y. (Forthcoming) Cross-Cultural Universality of Knowledge Attributions.

KORNBLITH, H. (2002). Knowledge and Its Place in Nature. Oxford University Press.

KORNBLITH, H. (2007). Naturalism and Intuitions. Grazer Philosophische Studien 74, 27-49.

LAURENCE, S., \& Margolis, E. (1999). Concepts and Cognitive Science, In E. Margolis \& S. Laurence (eds.) Concepts: Core Readings (p. 3-81). Cambridge, MA: MIT Press.

NAGEL, J. (2010). Epistemic Anxiety and Adaptive Invariantism. Philosophical Perspectives 24, 407-435.

NAGEL, J. (2012). Mindreading in Gettier Cases and Skeptical Pressure Cases. In Knowledge Ascription: New Essays, Jessica Brown and Mikkel Gerken, eds. (Oxford University Press, 2012), 171-191.

NAGEL, J. (2013). Knowledge as a Mental State. Oxford Studies in Epistemology 4, 275-310.

NAGEL, J., San Juan, V. \& Mar, R. (2013). Lay Denial of Knowledge for Justified True Beliefs. Cognition, 129, p. 652-661.

PAPAFRAGOU, A., Li, P., Choi, Y and Han, C. (2007). Evidentiality in Language and Cognition. Cognition 103: 253-99.

PIAGET, J., \& INHELDER, B. (1956). The child's conception of space. London: Routledge \& Kegan Paul.

POLlOCK, J. (1995). Cognitive Carpentry: A Blueprint for How to Build a Person. Cambridge, MA: MIT Press.

PREMACK, D., Woodruff, G. (1978). Does the chimpanzee have a theory of mind?. Behavioral and Brain Sciences, 1 (4), 515-526.

RAMSEY, W. (1992). Prototypes and Conceptual Analysis. Topoi 11:59-70.

ROSCH, E. (1973). On the internal structure of perceptual and semantic categories. in Cognitive Development and the Acquisition of Language, T. E. Moore (ed.), Academic Press, New York.

SAXE, R. (2005). Against simulation: the argument from error. Trends in cognitive sciences, 9(4), 174-179.

SOSA, E. (2002). Tracking, Competence, and Knowledge. In P. Moser (ed.), The Oxford Handbook of Epistemology, Oxford University Press, Oxford.

SCHWANENFLUGEL, P. (1991). Why are abstract concepts hard to understand? In Schwanenflugel, P. (ed), The psychology of word meanings. Hillsdale, NJ, Lawrence Erlbaum Associates, pp 223-250.

TOMASELlO, M., Call, J. (1997). Primate cognition. New York, NY, USA: Oxford University Press.

TURRI, J. (2013). A conspicuous art: putting Gettier to the Test. Philosophers' imprint, 13(10), $1-16$.

VOGEL, J. (1987). Tracking, Closure, and Inductive Knowledge. In S. Luper-Foy (ed.), The Possibility of Knowledge, Rowman and Littlefield.

WEINBERG, J., Nichols, S. and Stich, S. (2001). Normativity and Epistemic Intuitions. Philosophical Topics, 29, 429-460. 
WILLIAMSON, T. (2000). Knowledge and its Limits. New York: Oxford University Press.

Wittgenstein, L. (1953/2001). Philosophical Investigations. Blackwell Publishing. Zagzebski, L. (1994). The inescapability of Gettier problems. The Philosophical Quarterly, 44, 65-73.

\section{NoTES}

1 Another relevant issue from the naturalistic perspective is whether our concepts and intuitions are not interpersonally shared as we presuppose, a thesis claimed by Stephen Stich and colleagues and which stimulated the recent wave of experimental (empirical) philosophy (Weinberg, Nichols, and Weinberg, 2001). If this is the case and the concept of knowledge is not robust, but changes from culture to culture, for instance, then we have an explanation on why we cannot find a robust analysis. Since the initial charge from Stich and his colleagues (and the advance of empirical methodology), however, there has been a growing consonance of works showing the robustness of important epistemic intuitions across people and cultures. But this issue escapes from our scope here and we will not discuss it. For recent relevant work, see Nagel, San Juan \& Mar (2013), Turri (2013) and Kim \& Yuan (2015; Forthcoming).

2 George Bealer (1998), for instance, shares this basic premise but imposes certain rational constraints for something counting as an intuition, like it having the appearance of necessity and being robust in certain ways. His view, therefore, implies that concepts are a species of abstract entities and intuitions are a rational way to grasp those entities.

3 From now on we will use capital letters to refer to folk concepts.

4 Some languages like Turkish and Korean have grammaticalized evidentials that indicate the source of the asserted proposition, e.g., inference, testimony or own perception (Aikhenvald, 2004). This could suggest that in these cultures PERCEPTUAL KNOWLEDGE and INFERENTIAL KNOWLEDGE are basic level categories. However, experiments failed to find significant differences in the performance of young English-speakers and Korean-speakers regarding the tracking of evidential source, suggesting otherwise (Papafragou, 2007).

5 One possibility is that the task of judging the representativeness of knowledge situations triggers ad hoc judgments of typicality. To count as evidence of prototypical structure, however, those judgments should predict a number of other related tasks (Rosch, 1973).

6 Indeed, there is relative consensus in developmental and comparative psychology that the concept of knowledge is actually simpler and acquired first than the concept of belief. For a review, see Jennifer Nagel (2013).

7 The claim that there are different epistemic statuses and the use of expressions like "special status" and "good enough" may sound as if a piece of information must be very strongly supported to count as k-states. We are not trying to suggest that. Indeed, it is plausible that many stored information are simply internally considered knowledge by default. That is the case, for example, for most acquired information. Most outcomes of perceptual processes, most of our conclusions, most of the information that we receive by testimony, etc., are internally perceived as knowledge. Also, k-states are defeasible. Although much of our represented information is just considered knowledge by default, this fact, by its turn, does not mean that such a status is not defeasible. This is a platitude, actually. $8 \mathrm{I}$, therefore, do not dispute the evidence in developmental psychology suggesting that children go through stages of developments that use generalizations regarding epistemic states (Saxe, 2005). 